Nguyen, H.V., Tommelein, I.D., Martin, P. (2018). "Process-Based Cost Modeling Framework and Case Study." In: Proc. $26^{\text {th }}$ Annual Conference of the International. Group for Lean Construction (IGLC), González, V.A. (ed.), Chennai, India, pp. 46-57. DOI: doi.org/10.24928/2018/0523. Available at: www.iglc.net.

\title{
PROCESS-BASED COST MODELING FRAMEWORK AND CASE STUDY
}

\author{
Hung V. Nguyen', Iris D. Tommelein ${ }^{2}$, and Paul Martin ${ }^{3}$
}

\begin{abstract}
This paper provides a theoretical basis with reasons why traditional cost modeling methods are insufficient to support project delivery whereby product and process design are integrated and rapid cost feedback facilitates trade off analysis between multiple design alternatives. Traditional cost models do not sufficiently reflect cost changes due to changes in process design. This prompted our research into an alternative cost modeling method able to: (1) specify cost changes due to changes in product design, (2) specify cost changes due to changes in process design, and (3) provide rapid cost feedback to assist decision making during design/planning phases. This led to developing the Processbased Cost Modeling (PBCM) framework that is presented in this paper. The PBCM framework includes three phases: (1) collecting process and cost data, (2) mapping this data to Building Information Model (BIM) objects, and (3) providing cost feedback during design. The key contribution of this framework for modeling cost is that it takes into account product and process design features and can thus serve integrated project delivery teams while they explore production system design alternatives.
\end{abstract}

\section{KEYWORDS}

Process-based Cost Modeling, Cost Estimating, Target Value Design, Lean construction

\section{INTRODUCTION}

In current construction accounting practice, the cost of an installed component is the cost of materials plus the cost of all resources used to install that component (Means 2015). Traditional cost models such as regression models (Bledsoe 1992), parametric models (Skitmore and Marston 1999), and elemental estimating methods (Soutos and Lowe 2011) rely on historical data to model the cost of new designs. Historical cost databases provide some kind of average productivity and cost measured based on completed projects. The problem is that those projects may not have used methods to eliminate process waste or improve productivity, and their context may differ significantly. Consequently, using

1 BIM Process Manager, Herrero Builders, Inc. 2100 Oakdale Ave, San Franc., CA 94124, Lecturer, Civil and Envir. Engrg. Dept., UC Berkeley, hung-nguyen@ berkeley.edu, orcid.org/0000-0001-6625-2962.

2 Professor, Civil and Envir. Engrg. Dept., Director, Project Production Systems Lab., Univ. of California, Berkeley, CA 94720-1712, +1 510 643-8678, tommelein@berkeley.edu, orcid.org/0000-0002-99416596.

3 Project Exec. at XL Construction, Inc. 343 Sansome St. Suite 505 San Franc., CA 94104, Adj. Professor, UC Davis Extension, California, pmartin@xlconstruction.com, orcid.org/0000-0001-9148-6891. 
these productivity- and cost data, possibly coupled with outdated practices, tends to increase estimated durations, drive up estimated resource needs, and thus inflate estimated cost.

Researchers have criticized traditional cost models for their focus on resources rather than on processes. Wilson (1982) criticized these models' reliance on historical data to produce estimates of building or component cost without explicit consideration of their inherent variability in product design and installation processes. Bowen et al. (1987) argued that traditional cost models do not explain the systems they represent and suggested that realistic cost models must simulate the construction process and take into account the cost implications of the process used to construct buildings.

Li et al. (2003) and Bargstädt and Blickling (2004) modeled human resource activities to determine process durations and associated process costs during simulation of production processes. They estimate labor costs while playing the production process as a computer game by measuring resource consumption in the simulated processes. While this may yield more accurate estimates than those based on historic data, they require detailed process data that may be available only late in the construction documents phase. Moreover, it may be very time consuming and expensive to collect data and simulate construction processes. To facilitate estimators' judgment on cost implications of product customization, Staub-French and Fischer (2002) and Staub-French et al. (2003) proposed an activity-based cost model to help estimators customize a project's activities, resources, and resource productivity rates based on their preferences and the particular features in a given product model. This helps estimators more rationally adjust project activities and resource productivity rates but it does show estimators what the cost implications are of changes in process, such as transportation and site logistics, as the result of changes in product design.

\section{CURRENT PRACTICE OF COST MODELING TO INFORM TARGET VALUE DESIGN (TVD)}

Integrated Product-Process Design - as pursued on projects that use TVD - is a management practice that drives design to deliver customer value within project constraints (Ballard 2009). The TVD environment offers opportunities to project team members engaged in the design phase including: (1) Collocation and collaboration, (2) Set-Based Design exploring multiple design alternatives, (3) Frequent sharing of incomplete information, (4) Simultaneous design of product and process, (5) 3D Design/Modeling and digital prototyping, and (6) Trade contractor and supplier participating in design.

The TVD process results in identifying design alternatives, not only with different product cost and process cost, but also with different product features. As pointed out, traditional cost modeling methods are too granular to allow for trade-off analysis between alternatives of product- and process design especially as needed to support TVD. TVD teams need a cost modeling method able to: (1) quantify cost changes due to changes in product design (i.e., materials, shapes, or dimensions), (2) quantify cost changes due to changes in process design (i.e., sequencing, logistics, or construction), and (3) give rapid 
cost feedback to assist in decision making. Figure 1 presents the cost modeling process during Design Development on a project that uses TVD (Nguyen 2010).

Cost estimating practice applied during Design Development has not taken full advantage of opportunities provided when project teams pursue integrated product- and process design, such as those working in a TVD setting. Though project managers and detailers may be collocated, trade contractors' cost estimators may still work remotely in their own company office and have little access to information revealed in coordination meetings, logistics planning, and production planning. As a result, they may make assumptions on information already available, and estimate cost based on those. Such assumptions lead to 'contingency' built into the estimate to account for uncertainty. However, such contingencies could be eliminated if estimators were aware of discussions held during coordination meetings. Having cost estimators participate in key coordination meetings would make their estimate less padded with contingency and more accurately reflecting the current facts. Moreover, when evaluating design alternatives, the coordination team could benefit from immediate cost advice given by cost estimators.

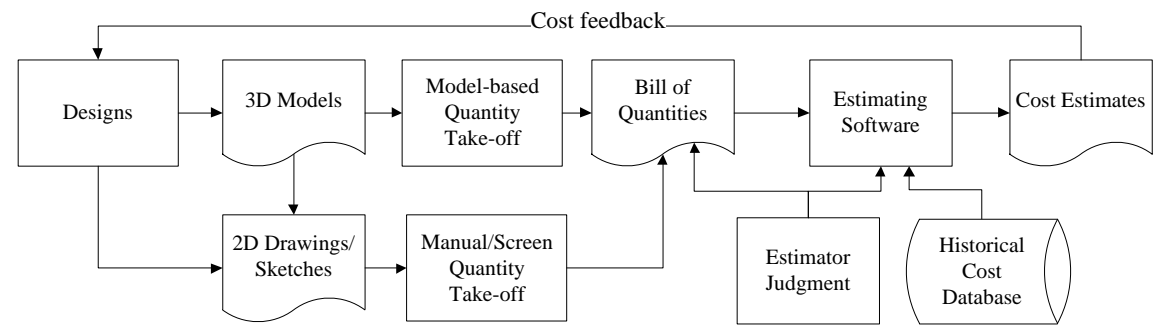

Figure 1: Cost modeling process during Design Development phase

Current cost estimating practice during Design Development has not taken full advantage of BIM. Though BIM has become a norm on many projects, cost estimators still perform quantity take-offs using 2D drawings extracted out of 3D models. By doing so, the design gets represented by multiple drawings (e.g., plans and elevations) thereby increasing the likelihood of an estimator missing or double counting individual design elements. In addition, quantity take-off on 2D drawings is time-consuming (Nguyen and Martin 2011). That time could be reduced by taking advantage of BIM, so as to free the estimator's time to perform more value adding activities such as helping their team with providing cost advice and value engineering. With the current estimating practice, upon completion of a bill of quantities (BOQ) especially in a large-scale project, a design may have changed, so that the BOQ and thus the cost estimate is out of date and possibly rendered useless.

\section{OVERVIEW OF PBCM FRAMEWORK}

The Process-based Cost Modeling (PBCM) framework presented in this paper is not intended to replace traditional cost models. Because the latter do not provide clear process information of the estimated items, PBCM is intended to supplement them by making process information explicit to designers, cost planners, and other team members. 
By linking a product model to cost data, PBCM may provide rapid cost feedback to design and lessen the time required to assemble cost updates to inform TVD.

The purpose of PBCM is to support the selection of a design alternative during Design Development. Accordingly, the model needs to give a relative cost and this can be useful even when it is approximate. To do this, the cost model should be capable of making both process-related cost and product-related cost explicit to designers when they are analyzing design alternatives. Process-related cost may include cost of material handling and transportation, site logistics, and site installation depending on the scope being considered.

This cost model is best applied in projects where key players from upstream to downstream of the project (such as the owner, architect, engineers, GC, trade contractors, suppliers) are members of the design team. It also can be used in more traditional project delivery systems with integrated approaches such as Design Build (DB), Construction Manager at Risk, and Multi-Prime with DB, where both the GC and trade contractors can be involved early in the design process. A design-assist approach used in combination with these project delivery systems may further facilitate the participation of trade contractors in design (Gil et al. 2001). Since such early involvement is limited when using Design-Bid-Build (DBB) as the project delivery model, a PBCM has few opportunities for effective application in DBB. While the owner in a DBB contract (especially a public sector owner) may engage contractors early in design, in order to avoid conflict of interest in bidding, they will usually exclude them from the bid list. Although those contractors may provide insightful process- and cost advice to designers and help estimate product- and process cost, those estimates may not be all that useful since the contractors later selected to do the work may use different means and methods for construction. Figure 2 presents key process steps of PBCM including three phases: (1) Capturing process cost data, (2) Attaching cost data to an object family, and (3) Creating cost feedback to a design team. 


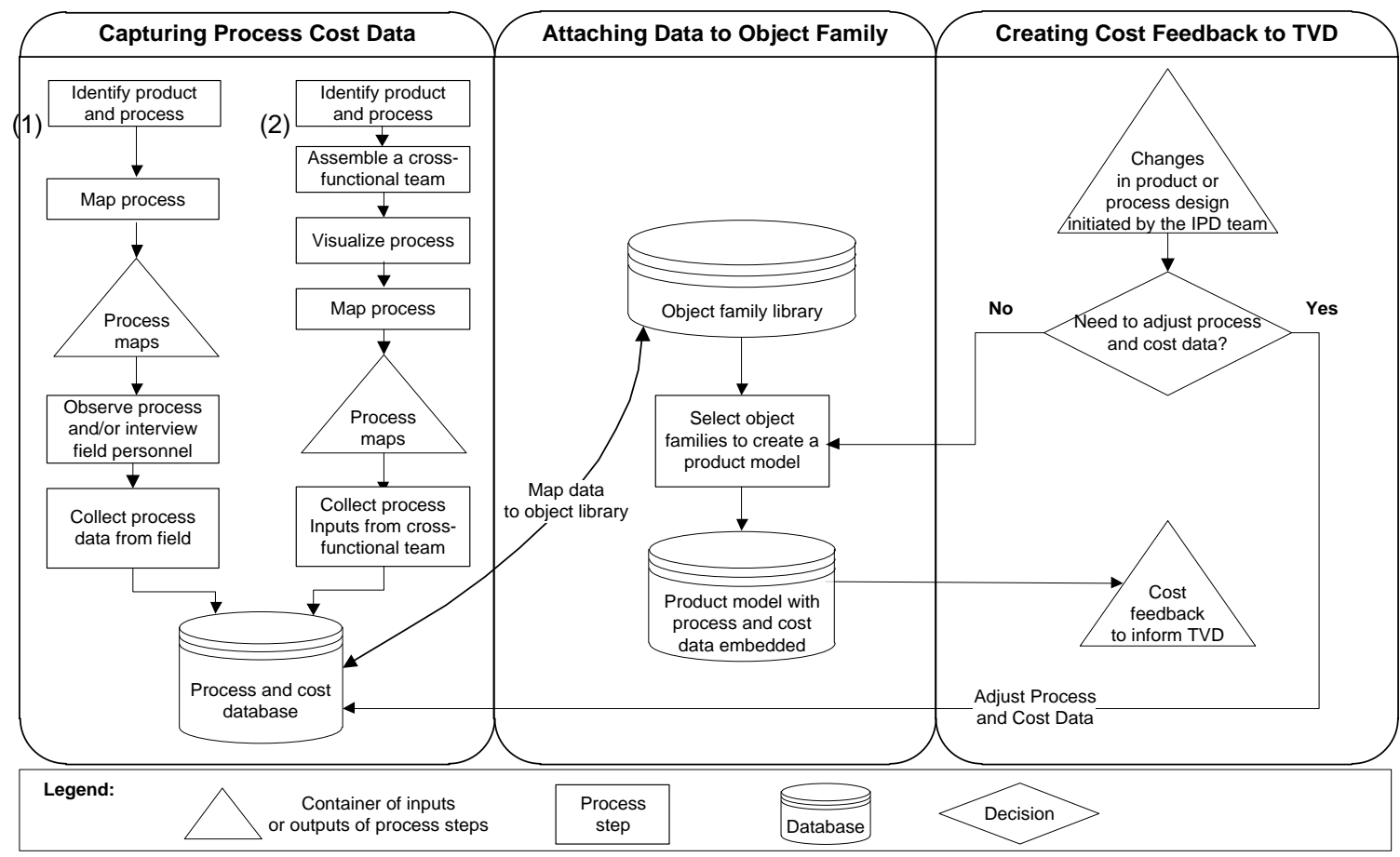

Figure 2: PBCM framework

\section{Capturing Process- and Cost Data}

Process- and cost data may be collected based on one of two scenarios: (1) products that have standard process designs and (2) products that require new process designs.

With standard products or systems (e.g., products Made-to-Stock (MTS) or Assembled to Order (ATO) (Tommelein et al. 2009)), it is possible for contractors to develop standard processes for installation and collect process data over time. In contrast, with products or systems with more unique designs, it may be more difficult if not impossible for contractors to develop standard processes for installation. The use of oneoff Engineered to Order (ETO) and Fabricated to Order (FTO) products tends to lead to variation in the duration of installation activities that vary significantly in process design or require new process design. Detail steps for collecting process data for products that require new process design are proposed as follows:

Step 1: Identify product and process: Select products or systems that have a high installation cost, pose a challenge to site logistics, require tight coordination between specialists, or contain process uncertainty.

Step 2: Assemble a cross-functional team The cross-functional team should include the representatives of the designer or the engineer, the GC, the fabricator or the supplier of the product or system, and the trade contractors who perform site installation work.

Step 3: Present process visualization of installation alternatives to the cross-functional team. The objectives of process visualization are to: (1) graphically display construction processes to the team, (2) facilitate the coordination between designers, GC, suppliers, 
and trade contractors to integrate product- and process design, and (3) help the team develop a common understanding of work conditions.

Step 4: Map the process. 4.a. Define process boundary; 4.b. Identify process steps for each specialty and specify hand-offs between specialties; 4.c. Map the process and alternatives.

For each design alternative, the cross-functional team provides data and knowledge to map out fabrication, logistics, and installation processes using process mapping. Process maps serve as a platform for the team to provide input data such as activities, sequencing alternatives, estimated duration of each step, estimated number of man-hours to complete each step, equipment, inventory space needs, constraints and coordination requirements from each party.

Step 5: Capture process data by getting input from the cross-functional team. The GC, designers, trade contractors, suppliers, and cost estimators provide data on each activity in the process map such as distance from fabrication shop to construction site, truck capacity, design quantities, crew composition, activity duration, and estimated unit cost for each cost driver. Process cost is calculated using process data and established rates for labor, equipment, and materials.

Step 6: Feed process- and cost data into a database, calculate cost of each activity, and allocate activity cost to each unit of product.

\section{CASE STUDY}

A case study presents the application of PBCM to evaluate the installation alternative of a Viscous Damping Wall (VDW) (Nguyen et al. 2009, Newell et al. 2011) system used in the Van Ness Campus project (VNC). A VDW consists of an inner steel plate connected to an upper floor girder, a steel tank connected to a lower floor girder, and a viscous fluid in the tank. The inner steel plate hangs in the viscous fluid. In case of an earthquake it will move and through friction dissipate energy into the fluid. It is used to reduce seismic accelerations and wind induced vibration in a structure. Although widely used in Japan, VNC is the first project in the United States to use a VDW system.

The VDW challenged logistics and field installation for many reasons: (1) delivery and installation of VDWs required coordination of multiple project participants, (2) members of the project delivery team had no previous experience in fabricating, transporting, and installing the VDW system, (3) as a seismic control device installed in between upper- and lower girders, the sequence of installing the VDW system affected the sequence of installing the whole structural steel system, (4) VNC construction site was in downtown San Francisco, surrounded with busy streets, and with very limited storage area on site, (5) the large size and heavy weight of each VDW unit added risks to the installation process. In order to optimize the integration of product- and process design, the integrated project delivery team wanted to explore different schemes and solutions for VDW installation.

The team established close collaboration between the estimator, the Virtual Design and Construction (VDC) staff, the designer, and trade contractors. This collaboration 
helped the estimator to understand how the 3D model is built, the data contained in the model, and limitations of the model-based quantity takeoff. At the same time, it helped the VDC staff and the designer to understand estimating needs and formats so that they can specify names and assemblies of model objects for estimating purposes. Under the guidance of the estimator, the trade contractors provided process related information and specified impacts to fabrication/field installation due to changes in product features.

With trade contractors on board during Design Development, the team created process maps that cover design, fabrication, packaging, transportation, and installation of important systems or components. With their field experience, trade contractors provided estimates of process data and estimated cost for their work scope. In this case study, the researcher provided 3D simulations of construction process to help the team focus discussion on constructability, logistics, make ready work, activity duration, crew composition, and types of equipment. The researcher helped facilitate the application of PBCM process and performed semi-structured interviews with structural steel team representatives and the VDW trade partner to evaluate the effectiveness of the PBCM method in evaluating design alternatives (Nguyen 2010). Figure 3 depicts a sample in which different types of data, collected from the process mapping session, are input to a database.

\section{Attaching Process Cost Data to Object Family}

Figure 4 illustrates the linking of three different family types of the VDW to process- and cost data pertaining to four alternatives of installation. The product model contains object families created by the architect, the engineer, or the trade contractor. The database contains product and cost data collected for the project. Each object family type, e.g., the VDW size 7'x9', is linked to process- and cost data of its four installation alternatives including (1) pre-bolting, (2) inserting, (3) sequencing, and (4) pre-bolting with kitting.

\section{Providing Cost Feedback to TVD}

When designers consider a change in product (i.e., product family type) or process (i.e., method of installation), they may swap a current product family in the product model with another one in the model's product library and select an alternative of installation to see the impact on final cost. If the team sees the need for modifying process- and cost data, they can access the database to make adjustments. For example, team members may adjust crew composition, activity durations, transportation distance, etc. according to conditions of the current project. Since process- and cost data are linked to the object family, the team will be instantly provided with related changes in both product cost and process cost. The linking of data between product model and process cost model acts as an integrated product/process/cost model that can provide quick cost feedback to designers. 


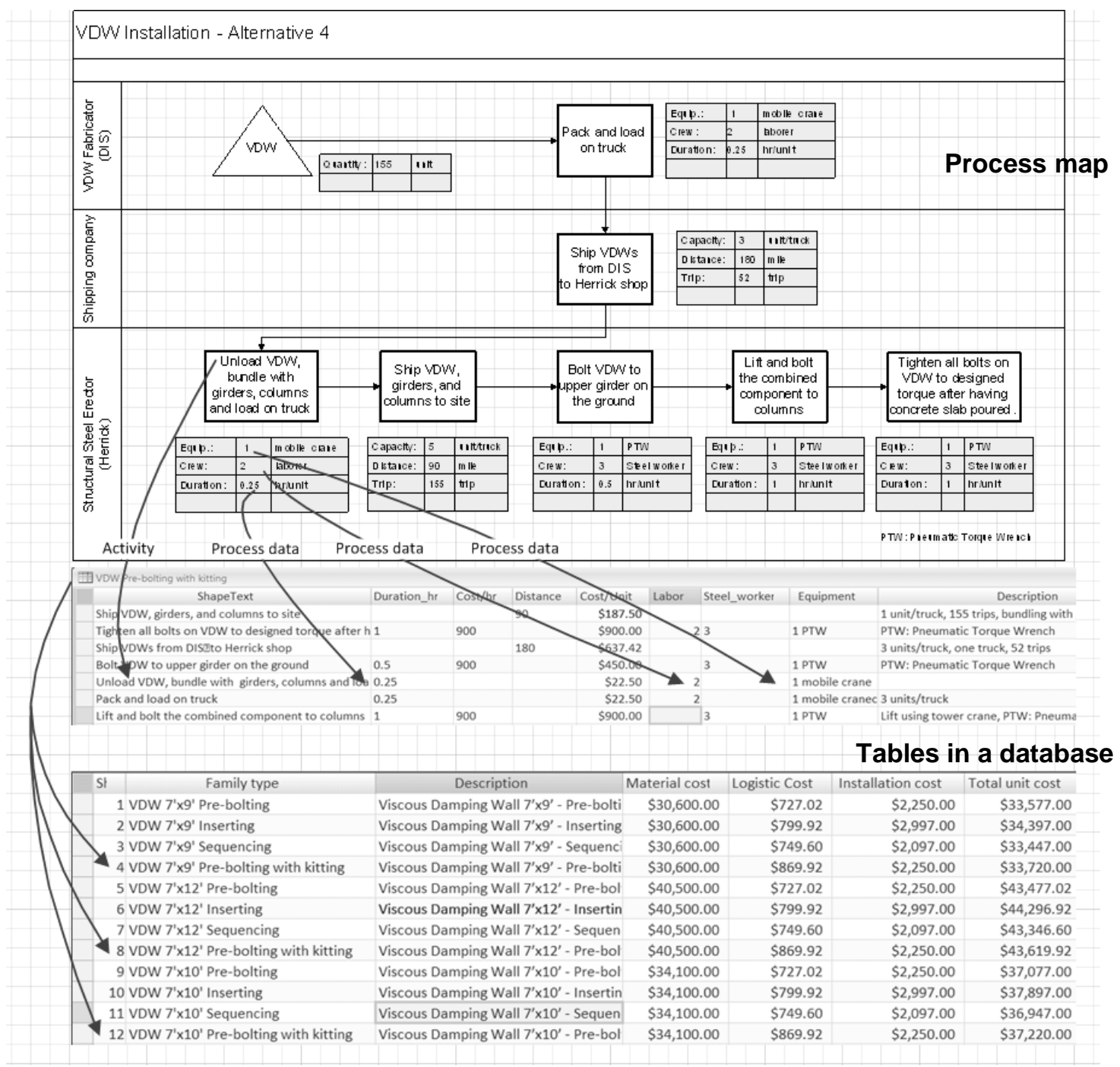

Figure 3: Data input from process map to database

This cost data can be included in a quantity schedule within a BIM authoring software (e.g., Autodesk Revit) to provide cost feedback to the design team in the course of selecting product or process alternatives. Data such as VWD counts can be extracted from the model to calculate a total cost (Figure 5). 


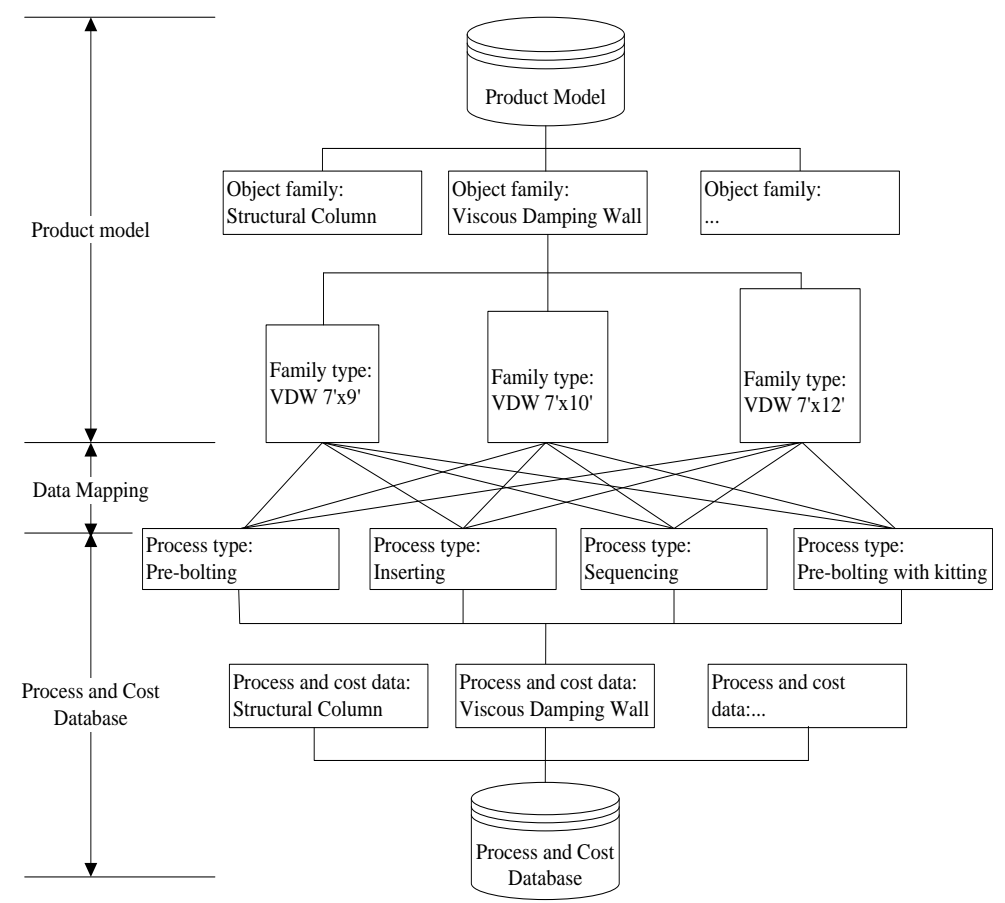

Figure 4: Linking object family types of a product model to process cost data

\begin{tabular}{|c|c|c|c|c|c|c|c|c|}
\hline \multicolumn{9}{|c|}{ Viscous Damping Wall } \\
\hline Family and Type & Description & Material Cost & Installation $\mathrm{Co}_{0}$ & Logistic Cost & Total Unit Cost & Count & Total Cost & Manufacturer \\
\hline VDW 7'x9': VDW 7'x9' Pre-bolting with $k$ & 9'Viscous & 30600 & 2250 & 869 & 33719 & 76 & 2562713 & DIS \\
\hline VDW 7'x12': VDW 7'x12' Pre-bolting wit & $12^{\prime}$ Viscous & 40500 & 2250 & 869 & 43619 & 79 & 3445973 & DIS \\
\hline
\end{tabular}

Figure 5: Cost feedback for 'Pre-bolting with kitting' installation alternative

Figure 5 depicts a VDW schedule view in Autodesk Revit: two VDW family types are used in this design including 76 units of VDW 7'x9' and 79 units of VDW 7'x12'. The selected method of installation is 'Pre-bolting with kitting'. Given the selected family types, the method of installation, and the quantities of VDW extracted from the design model, the total estimated cost for this design alternative is $\$ 2,562,713+\$ 3,445,973=$ $\$ 6,008,686$.

Figure 6 illustrates a team considering alternative means for installing the VDW. A team member may replace the object family type 'Pre-bolting with kitting' with 'Sequencing', 'Inserting', or 'Pre-bolting' installation method to see how cost will be effected. Values in related fields such as material cost, installation cost, or total cost, etc. will change to reflect the choice of installation method. When the quantity and the type of VDW get changed during design, this information will be immediately updated in the model, and a new total cost is calculated automatically.

With this method, estimators can connect any type of data contained in the processand cost database to a BIM object. This method provides a link between a model element and its related cost and process data. This link enables designers to have immediate product and process cost feedback during design. The method is most useful in informing 
the decision-making process when it contains cost and process information provided by the trade contractors who will actually implement the work.

\begin{tabular}{|c|c|c|c|c|c|c|c|c|}
\hline \multicolumn{9}{|c|}{ Viscous Damping Wall } \\
\hline Family and Type & Description & Material Cost & Installation $\mathrm{Co}$ & Logistic Cost & Total Unit Cost & Count & Total Cost & Manufacturer \\
\hline VDW 7'x9': VDW/ 7'x9' Sequencing & $9^{\prime}$ Viscous & 30600 & 2097 & 749 & 33446 & 76 & 2541941 & DIS \\
\hline VDW 7'x12': VDW 7'x12' Sequencing & $712^{\prime}$ Viscous & 40500 & 2097 & 749 & 43346 & 79 & 3424381 & DIS \\
\hline 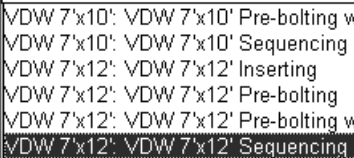 & kitting & & $\Delta$ & & & & & \\
\hline
\end{tabular}

Figure 6: Cost feedback for 'Sequencing' installation alternative

\section{CONCLUSIONS}

This paper reviews limitations of traditional cost modeling methods and explores how an integrated product-process-based cost modeling method may be established and applied to facilitate Target Value Design (TVD). It formulated directions for developing the PBCM framework. Findings from the literature review and observations of the current state of cost modeling during the Design Development phase in the TVD environment revealed (1) the lack of an effective cost modeling method to inform TVD during Design Development and (2) the lack of a framework to take advantage of BIM in estimating product- and process cost. This paper delivered a proof of concept for a PBCM framework and validated it through application on a case study using action research. PBCM has more advantages in supporting TVD than traditional cost estimating methods have.

In addition, process-based cost estimating used in connection with BIM can provide more useful data to compare design solutions than traditional cost models do. Process cost data that comes out of the PBCM can be entered to BIM as properties of an assembly or a system, so that designers will instantly have cost feedback on how total cost is affected by their changes in product design or process design. By linking cost data to a product model (BIM), a PBCM provides rapid cost feedback to designers and lessens the time required to assemble cost updates that are to inform those involved in TVD. By integrating process- and product cost data with BIM, an integrated product/process/cost model helps to streamline the design process and reduce rework in the design/estimate/redesign iteration. In addition, the implementation of the PBCM method helps the IPD team to maintain a knowledge database of product design, process design, and their costs for future projects.

Further case studies should be conducted on different types of products or systems to test and to further refine steps to be included in the implementation of PBCM. A project team can validate a PBCM using feedback of actual costs to review and adjust the process- and cost data as well as to adjust PBCM for estimating costs of future projects. Further research is required to study the mechanism of adjusting PBCM based on feedback from the actual cost data. 


\section{ACKNOWLEDGMENTS}

The development of the ideas presented in this paper was supported in part by gifts made to the Project Production Systems Laboratory (P2SL) and by funding from the Vietnam Education Foundation (VEF). All support is gratefully acknowledged. Any opinions, findings, conclusions, or recommendations expressed in this paper are those of the authors and do not necessarily reflect those of contributors to P2SL nor VEF.

\section{REFERENCES}

Ballard, G. (2009). "An Update on Target Value Design.” Presentation Slides, Design Forum, June 18-19, St. Louis, MO. www.leanconstruction.org/media/docs//wpapers/ designforum200906/2_Update_on_Target_Value_Design/2_TVD_Update_ppt.pdf.

Bargstädt, H.J., and Blickling, A. (2004). "Effective cost estimate and construction processes with 3D interactive technologies: Towards a virtual world of constt. sites." Proc. $X^{\text {th }}$ Int'l. Conf. Comp. Civil and Bldg. Engrg.. ICCCBE, Weimar, Bauhaus Univ.

Bledsoe, J.D. (1992). Successful Estimating Methods: From Concept to Bid. Kingston, MA, R.S. Means.

Bowen, P.A., Wolvaardt, J.S. and Taylor, R.G. (1987). "Cost Modeling: a ProcessModeling Approach.” Bldg. Cost Modeling and Comp., 15-24, London, E\&FN Spon.

Gil, N., Tommelein, I.D., Kirkendall, R.L. and Ballard, G. (2001). "Leveraging Specialty Contractor Knowledge in Design-Build Organizations." Engineering, Construction, and Architectural Management (ECAM), October/December, 8(5/6), 355-367.

Li, H., Ma, Z., Shen, Q., Kong, S. (2003). "Virtual experiment of innovative construction operations." Automation in Construction, 12(5): 561-575

NIBS (2015). "Whole Building Design Guide." National Institute of Building Sciences. http://www.wbdg.org. Accessed November 102015.

Nguyen, H.V., Lostuvali, B., Tommelein I.D. (2009). "Decision Analysis Using Virtual First-Run Study of a Viscous Damping Wall System." Proc. 17 $7^{\text {th }}$ Annual Conf. Int'l Group for Lean Construction (IGLC 17), 15-17 July, Taipei, Taiwan, 371-382.

Nguyen, H. (2010). Process-Based Cost Modeling to Support Target Value Design. PhD Diss., University of California, Berkeley, CA.

Nguyen, H. and Martin, P. (2011). 'Model-based Quantity Takeoff and Estimate Validation at the Cathedral Hill Hospital Project.' Am. Soc. of Professional Estimators. Estimating Today Magazine, May.

Newell, J., Love, J., Sinclair, M., Chen, Y., and Kasalanati, A. (2011). "Seismic Design of a 15 Story Hospital Using Viscous Wall Dampers." Structures Congress, pp. 815826.

Skitmore, M. and Marston, V. (Ed.) (1999). Cost Modeling, E\&FN Spon, London.

Soutos, M. and Lowe, D. (2011). "Elemental cost estimating: current UK practice and procedure." Journal of Financial Management of Property and Construction, 147-162.

Staub-French, S., Fischer M. (2002). "Generating and Maintaining Activity-based Cost Estimates with Feature-Based Product Models." $19^{\text {th }}$ International Symposium on Automation and Robotics in Construction, Washington D.C., USA, Sep. 23-25. 
Staub-French, S., Fischer, M., Kunz, J., and Paulson, B. (2003). "A Generic FeatureDriven Activity-Based Cost Estimation Process.” Adv. Engineering Informatics, 17(1), 23-39

Tommelein, I.D., Ballard, G. and Kaminsky, P. (2009). "Supply Chain Management for Lean Project Delivery." Ch. 6 in O'Brien, W.J., Formoso, C.T., Vrijhoef, R. and London, K.A. (eds.). Constr. Supply Chain Mgmt. Handbook. CRC Press, Boca Raton, FL.

Wilson, A.J. (1982). "Experiments in Probabilistic Cost Modeling." Building Cost Techniques: New Direction, Brandon P.S., Ed., E\&FN Spon, London. 